(C) The Authors 2012

\title{
Leucine and methionine deficiency impairs immunity to gastrointestinal parasites during lactation
}

\author{
Panagiotis Sakkas ${ }^{1}$ 化, Leigh A. Jones ${ }^{1}+\mathbb{\delta}$, Jos G. M. Houdijk ${ }^{1 *}$, Spiridoula Athanasiadou ${ }^{1}$, Dave P. Knox ${ }^{2}$ \\ and Ilias Kyriazakis ${ }^{1} \|$ \\ ${ }^{1}$ Animal Health, SAC, Roslin Institute Building, Easter Bush, West Mains Road, Edinburgh EH9 3JG, UK \\ ${ }^{2}$ Parasitology Division, Moredun Research Institute, Penicuik EH26 OPZ, UK
}

(Submitted 12 October 2011 - Final revision received 25 January 2012 - Accepted 8 February 2012 - First published online 10 May 2012)

\begin{abstract}
Lactating rats reinfected with Nippostrongylus brasiliensis fed low-crude protein (CP) foods show reduced lactational performance and less resistance to parasites compared with their high-CP counterparts. Here, we hypothesised that feeding high-CP foods deficient in specific essential amino acids (AA) would result in similar penalties. Second-parity lactating rats, immunised with $1600 \mathrm{~N}$. brasiliensis infective larvae before mating, were fed foods with either 250 (high protein; HP) or 150 (low protein; LP) g CP/kg, or were HP deficient in either leucine (HP-Leu) or methionine (HP-Met). On day 1 of lactation, litter size was standardised at twelve pups. On day 2, dams were either reinfected with $1600 \mathrm{~N}$. brasiliensis larvae or sham-infected with PBS. Dams and litters were weighed daily until either day 8 or 11, when worm burdens, and inflammatory cells and systemic levels of $N$. brasiliensis-specific Ig isotypes were assessed. Data from five out of sixteen HP-Met rats were omitted due to very high levels of food refusals from parturition onwards. Relative to feeding HP foods, feeding LP, HP-Met and HP-Leu foods reduced dam weight gain and, to a lesser extent, litter weight gain, and increased the number of worm eggs in the colon, indicative of a reduction in resistance to parasites. However, only feeding LP and HP-Leu foods resulted in increased worm numbers, while none of the feeding treatments affected systemic Ig, mast and goblet cells, and eosinophil numbers. The present results support the view that resistance to parasites during lactation may be sensitive to specific essential AA scarcity.
\end{abstract}

Key words: Leucine: Methionine: Lactation: Nematodes

It has been repeatedly shown that dietary protein supplementation at times of protein scarcity results in improved resistance and the expression of immunity towards gastrointestinal nematodes in periparturient mammal hosts $^{(1-3)}$, including laboratory rodents ${ }^{(4-7)}$. This may be related to the increased protein demands that the periparturient period imposes on the parasitised host, i.e. for milk production, as it has been suggested that scarce protein supply may be preferentially allocated to reproductive rather than immune functions ${ }^{(8,9)}$. As host responses following increased supply of dietary protein would be responses to dietary essential and conditionally essential amino acids (AA), it may be expected that their reduced supply can lead to reduced expression of immunity. Both innate and acquired immune responses are dependent upon adequate provision of AA for the synthesis of antigen-presenting molecules, Ig, cytokines and acute-phase proteins as well as for the provision of energy-providing substrates either directly, or following their conversion to other AA (e.g. glutamine) or to glucose $\mathrm{e}^{(10,11)}$. At the same time, requirements for protein and/or AA may also increase as a direct consequence of metabolic changes associated with inflammation and infection ${ }^{(12)}$ and the physiological status of the animal, such as pregnancy and lactation ${ }^{(13)}$. The fact that $30-50 \%$ of essential AA in the food may be catabolised by the small intestine ${ }^{(14,15)}$ is indicative of their role in gut integrity, function and local immune response ${ }^{(16,17)}$.

Herein we used a laboratory model ${ }^{(4)}$ to investigate the effect of reduced supply of two essential AA on host resistance and lactational performance (dam and litter weight gain). Our

Abbreviations: AA, amino acids; CP, crude protein; EIC, eggs in the colon; FEC, faecal egg count; HP, high protein; HP-Leu, high protein with leucine levels as in low protein; HP-Met, high protein with methionine levels as in low protein; LP, low protein; PBW, parturition body weight; SAA, sulphur-containing amino acids.

*Corresponding author: J. G. M. Houdijk, fax +44 1315353121, email jos.houdijk@sac.ac.uk

†Joint first authors.

$\ddagger$ Present address: Animal Nutrition Group, Wageningen University, PO Box 338, 6700 AH Wageningen, The Netherlands.

$§$ Present address: Singapore Immunology Network (SIgN), 8A Biomedical Grove, IMMUNOS Building 3-4, BIOPOLIS 138648, Singapore.

|| Present address: School of Agriculture, Food and Rural Development, Newcastle University, Newcastle NE1 7RU, UK. 
expectation was that single AA scarcity would impair protein synthesis in the host, with penalties on both its resistance and resilience to parasitic infection. Although there is an abundance of literature on the effects of individual AA deficiency on food intake ${ }^{(18)}$, performance ${ }^{(19)}$ and immune responses ${ }^{(20)}$ of growing animals, to our knowledge, this is the first study on specific AA deficiency in periparturient parasitised hosts.

In the present study, we focused on leucine and methionine, which have both been implicated in host responses to parasitism. Leucine requirements are increased during parasitism $^{(21)}$, as parasitised hosts show an increased intestinal metabolism of leucine and consequently reduced availability of leucine for other tissues. In addition, lactation increases leucine requirements, as an increased channelling of leucine from the blood flow to the mammary gland has been observed $^{(22,23)}$. In lactating rats, this increase may be up to $35 \%$ higher than that of non-lactating rats ${ }^{(24)}$.

Methionine, as the only essential sulphur-containing AA (SAA) and a precursor to a number of other SAA ${ }^{(25)}$, plays pivotal roles in protein synthesis, maintenance of gut functions and regulation of the mucosal response to antigens ${ }^{(25,26)}$. There is evidence suggesting that demand for SAA may be increased during gastrointestinal nematode infections ${ }^{(27,28)}$, probably due to the loss of SAA-rich endogenous protein via increased sloughing of epithelial cells and especially mucin secretion ${ }^{(29)}$. Importantly, methionine supplementation of growing rats infected with Nippostrongylus brasiliensis has resulted in a reduction of worm burdens ${ }^{(30)}$.

In the present experiment, we tested the null hypothesis that the reduced provision of either leucine or methionine, at high levels of other AA intake, will similarly penalise lactational performance and resistance to $N$. brasiliensis as a consequence of reduced AA availability to maintain the protective immune response.

\section{Experimental methods}

\section{Animals, housing and feeding strategy during gestation}

All experimental procedures were approved by the SAC Ethical Review Committee (ED AE 24/2007) and carried out under Home Office authorisation (PPL 60/3626). A total of seventytwo second-parity female Sprague-Dawley rats (Charles River UK Limited) were housed in a room where ambient temperature was maintained at $21^{\circ} \mathrm{C}$, relative humidity ranged from 45 to $65 \%$, and artificial lighting was provided between 08.00 and 18.00 hours. Rats were individually housed in solid-bottomed cages with fresh sawdust provided weekly. Shredded plastic bubble wrapping for nesting material was provided $3 \mathrm{~d}$ before the expected parturition date. Wire-bottomed cages were used during mating and for faeces collection during the primary infection as described previously ${ }^{(31)}$. For mating, female rats were placed with a proven male breeder and mating was confirmed through the presence of a vaginal plug.

Until mating was confirmed, rats were given ad libitum access to standard rat chow (Rat and Mouse No. 3; Special Diet Services). After mating was confirmed, rats were given ad libitum access to a high-protein food, with $210 \mathrm{~g}$ digestible crude protein (CP) and 16.4 MJ metabolisable energy/kg DM until $10 \mathrm{~d}$ into gestation to allow for the establishment of pregnancy and placental development. Rats were then transferred to a low-protein food containing $60 \mathrm{~g} \mathrm{CP}$ and $17 \cdot 3 \mathrm{MJ}$ metabolisable energy/kg DM, which was given until parturition. This feeding protocol was used to reduce body protein reserves during the second half of gestation in order to maximise the degree of protein AA scarcity during lactation when rats would be fed low-protein foods ${ }^{(4,32)}$.

\section{Feeding treatments}

Upon parturition (day 0), dams were allocated to one of four feeding treatments, i.e. low protein (LP), high protein (HP), $\mathrm{HP}$ with leucine levels as in low protein (HP-Leu) and $\mathrm{HP}$ with methionine levels as in low protein (HP-Met). The LP and HP foods were formulated to supply 150 and $250 \mathrm{~g}$ $\mathrm{CP} / \mathrm{kg}$, respectively. These $\mathrm{CP}$ levels were chosen on the basis of previous observations where lactating rats fed foods supplying $150 \mathrm{~g} \mathrm{CP} / \mathrm{kg}$ have shown significantly reduced lactational performance, elevated worm burdens and penalised expression of immunity compared with those receiving $250 \mathrm{~g}$ $\mathrm{CP} / \mathrm{kg}^{(6,7)}$. The protein source used for the LP food was methionine-enriched casein, and the LP food was the basis for all other foods. Casein was methionine-enriched, to overcome its natural deficiency in SAA content ${ }^{(33)}$, as our aim was for LP foods to be balanced in their AA profile. The HP food was prepared by adding a purified AA mixture to the LP food at the expense of starch and sucrose (Table 1) to

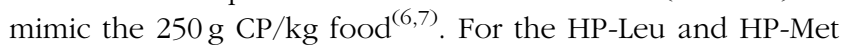
foods, leucine and methionine were likewise replaced in the added AA mixture with starch and sucrose. The resulting composition of the four experimental foods is presented in Table 1. Daily allowances were offered at $90 \%$ of observed DM intake during a previous experiment where similar diets were fed ad libitum ${ }^{(5)}$, using dam parturition body weight (PBW) as a scaling factor. Foods were offered in increasing amounts during lactation, reflecting the natural increase in

Table 1. Composition of the experimental foods used during lactation

\begin{tabular}{lcccc}
\hline & \multicolumn{4}{c}{ Experimental foods } \\
\cline { 2 - 5 } & HP & HP-Leu & HP-Met & LP \\
\hline Ingredients (g/kg fresh matter) & & & & \\
Casein* & 150 & 150 & 150 & 150 \\
Amino acid mixturet & 100 & 91 & 96 & 0 \\
Starch & 232 & 238 & 235 & 299 \\
Surcose & 116 & 119 & 117 & 149 \\
Maize oil & 150 & 150 & 150 & 150 \\
Vitamins & 50 & 50 & 50 & 50 \\
Minerals & 50 & 50 & 50 & 50 \\
Maize flour & 43 & 43 & 43 & 43 \\
Choline & 7 & 7 & 7 & 7 \\
Lecithin & 2 & 2 & 2 & 2 \\
Alphacel & 100 & 100 & 100 & 100 \\
\hline
\end{tabular}

$\mathrm{HP}$, high protein; HP-Leu, HP with leucine levels as in low protein; HP-Met, HP with methionine levels as in low protein; LP, low protein.

* Casein was enriched with methionine (casein:methionine ratio was 99:1).

†The amino acid mixture included in the experiment foods HP, HP-Leu and HPMet represented methionine-enriched casein, or that without leucine, or that without methionine, respectively. 
food intake with time as observed in previous experiments using this animal-parasite model system ${ }^{(4,5)}$. Food offered averaged $21,25,33$ and $41 \mathrm{~g} \mathrm{DM} / \mathrm{d}$ during days 1-2, 3-5, 6-8 and 9-11, respectively. Foods offered during lactation were sampled during their preparation for the analysis of DM, CP (Kjeldahl-N × 6.38), diethyl ether extract, ash, aciddetergent fibre, starch, sucrose and AA profile (Table 2).

\section{Infection protocol}

All rats received a primary infection of 1600 third-stage infective larvae of $N$. brasiliensis on day -37 (with day 0 as mean achieved parturition date), which were suspended in $0.5 \mathrm{ml}$ sterile PBS that was subcutaneously injected in the hind leg. On day 2, rats were either reinfected with 1600 third-stage infective larvae $N$. brasiliensis or sham-infected with PBS (primary infection only). The $N$. brasiliensis strain used was maintained at Moredun Research Institute through passage in growing Sprague-Dawley male rats.

\section{Experimental design}

The effects of the four feeding treatments were assessed on lactational performance and on parasitological and

Table 2. Chemical composition of the experimental foods used during lactation

\begin{tabular}{|c|c|c|c|c|}
\hline & \multicolumn{4}{|c|}{ Experimental foods } \\
\hline & $\mathrm{HP}$ & HP-Leu & HP-Met & LP \\
\hline \multicolumn{5}{|c|}{$\begin{array}{l}\text { Chemical composition (g/kg DM } \\
\text { unless otherwise stated) }\end{array}$} \\
\hline DM ( $\mathrm{g} / \mathrm{kg}$ fresh matter) & 679 & 689 & 689 & 672 \\
\hline $\mathrm{ME}(\mathrm{MJ} / \mathrm{kg})^{\star}$ & $15 \cdot 9$ & $15 \cdot 9$ & $15 \cdot 9$ & $15 \cdot 9$ \\
\hline $\mathrm{CP}$ & 237 & 227 & 235 & 150 \\
\hline Ash & 39 & 39 & 38 & 38 \\
\hline Acid-detergent fibre & 66 & 61 & 64 & 63 \\
\hline Diethyl ether extract & 150 & 148 & 149 & 150 \\
\hline Total sugars & 177 & 185 & 178 & 209 \\
\hline Starch & 253 & 248 & 252 & 313 \\
\hline \multicolumn{5}{|l|}{$A A(g / k g ~ D M)$} \\
\hline Leu & 23.6 & 13.9 & $24 \cdot 3$ & $13 \cdot 6$ \\
\hline Met & $9 \cdot 1$ & 8.9 & 5.5 & $5 \cdot 2$ \\
\hline Lys & 19.6 & $19 \cdot 3$ & $19 \cdot 9$ & 11.5 \\
\hline Thr & $10 \cdot 3$ & $10 \cdot 2$ & $10 \cdot 3$ & $6 \cdot 1$ \\
\hline Trp & 3.1 & $3 \cdot 2$ & $3 \cdot 2$ & 1.9 \\
\hline Arg & 9.2 & $9 \cdot 0$ & $9 \cdot 2$ & $5 \cdot 1$ \\
\hline Ile & $13 \cdot 1$ & $12 \cdot 4$ & $12 \cdot 8$ & $7 \cdot 2$ \\
\hline Val & $16 \cdot 1$ & $15 \cdot 9$ & $16 \cdot 5$ & $9 \cdot 3$ \\
\hline His & $7 \cdot 0$ & $7 \cdot 1$ & $7 \cdot 3$ & 4.2 \\
\hline Phe & $12 \cdot 2$ & $12 \cdot 1$ & $12 \cdot 5$ & $7 \cdot 2$ \\
\hline Cys & $1 \cdot 1$ & $1 \cdot 1$ & $1 \cdot 1$ & 0.8 \\
\hline Gly & 4.8 & 4.7 & 4.8 & $2 \cdot 7$ \\
\hline Ser & $13 \cdot 0$ & $12 \cdot 8$ & $12 \cdot 8$ & 7.9 \\
\hline Pro & $25 \cdot 6$ & $27 \cdot 5$ & 28.4 & 14.4 \\
\hline Ala & 7.5 & 7.4 & $7 \cdot 6$ & 4.5 \\
\hline Asp & 17.4 & $17 \cdot 2$ & $17 \cdot 6$ & $10 \cdot 3$ \\
\hline Glu & 54.0 & $52 \cdot 7$ & 53.9 & $30 \cdot 6$ \\
\hline
\end{tabular}

$\mathrm{HP}$, high protein; HP-Leu, HP with leucine levels as in low protein; HP-Met, HP with methionine levels as in low protein; LP, low protein; ME, metabolisable energy; $C P$, crude protein; $A A$, amino acids.

* Food ME content was calculated by multiplying its contents of protein (casein + $A A$ ), digestible carbohydrates (starch, sucrose and maize flour) and fat (maize oil) with the ME contents of protein $(17 \mathrm{MJ} / \mathrm{kg})$, carbohydrates $(17 \mathrm{MJ} / \mathrm{kg})$ and fat $(38 \mathrm{MJ} / \mathrm{kg})^{(53)}$. immunological variables on days 8 and 11 (corresponding to days 6 and 9 post-secondary infection, respectively). These two sampling time points post-secondary infection were included, as previous studies with the same model suggested that the nutritional sensitivity of host resistance and the expression of immunity in this model may vary with time ${ }^{(5-7)}$. All rats in these eight factorial feeding treatmentendpoint combinations (four feeding treatments $x$ two endpoints) received the secondary infection. Sham-infected control rats were also included until day 8 only (first endpoint) for each feeding treatment to assess the effect of reinfection on lactational performance and the expression of immunity. This resulted in a total of twelve experimental treatments. Rats were blocked for PBW and were randomly allocated to these twelve treatments; on the morning, parturition was observed to be complete. Total sample size aimed for was $n 6$ for infected rats and $n 5$ for control rats. However, the minimum realised sample size was $n 5$ for infected rats and $n 4$ for control rats due to infertility, miscarriage or dead pups.

\section{Performance and parasitology}

Body weight and food intake. Rats were weighed daily throughout the experiment, and daily body weights taken post-parturition were used to calculate lactational dam weight gain. The pups were counted and the whole litter weighed daily from day 0 . Litter size was standardised at twelve pups on day 1 to have equal initial nutrient demands. Dam and litter weights from day 1 onwards were used to calculate litter weight gain. Any refusals observed during the lactation period were weighed to assess observed DM intake.

Faecal egg counts. A faecal egg count (FEC, in eggs/g fresh faeces) was performed $7 \mathrm{~d}$ after the primary infection (day -30) to confirm establishment of infection. A second FEC was performed on day -23 to confirm parasite expulsion. To this effect, faeces were collected through overnight housing on bottom-wired cages ${ }^{(31)}$ and FEC were performed using a modified saturated salt flotation method ${ }^{(34)}$.

Worm burden and nematode eggs in the colon. Rats were killed humanely through gradually increasing ambient $\mathrm{CO}_{2}$ concentration for parasitological assessment and immune responses (see below). Nematodes were harvested from the small intestine as outlined previously ${ }^{(31)}$. The resulting worms were then stored in formaldehyde for subsequent counting and assessment of sex and maturation status according to morphology. The contents of the large intestine were weighed and assessed for worm eggs as described for FEC above. This was then multiplied by the large-intestinal content weight to obtain the total number of nematode eggs in the colon (EIC)

\section{Immunology}

Inflammatory cells. A $2 \mathrm{~cm}$ sample of the small intestine at a $25 \mathrm{~cm}$ distance from the pylorus was washed with PBS to collect worms for total worm counts (see above) and then fixed in $4 \%$ paraformaldehyde for $6 \mathrm{~h}$. The fixative was then replaced by $70 \%$ ethanol. Resulting intestinal samples were 
wax embedded and sections taken and stained using standard histological techniques. Sections were stained for counting three types of inflammatory cells, i.e. eosinophils (carbol chromatrope 2R), goblet cells (alcian blue and counterstaining with periodic acid-schiff) and mast cells (toluidine blue) Cells were enumerated by counting ten complete, well-orientated, villus crypt units per section and results are expressed as the number of cells/villus crypt unit.

Systemic antibodies. Terminal blood samples taken from the chest cavity following heart puncture were centrifuged at $200 \mathrm{~g}$ for $10 \mathrm{~min}$ and serum supernatants stored at $-70^{\circ} \mathrm{C}$ for determination of antibody levels. The concentration of parasite-specific IgA, IgG, IgG1, IgG2a, IgG2b and IgE antibodies was measured by ELISA. Briefly, ELISA plates were coated with $1 \mu \mathrm{g} / \mathrm{ml}$ adult somatic $N$. brasiliensis antigen ${ }^{(35)}$ and then blocked overnight at $4^{\circ} \mathrm{C}$ with $10 \%$ dried milk powder in PBS. Diluted serum samples (1:1000) were added to the plate and incubated at room temperature for $1 \mathrm{~h}$. Antibody isotypes were detected by the addition of rat-specific secondary antibodies at one in 5000 dilution for anti-rat $\operatorname{IgE}, \operatorname{IgG}, \operatorname{IgG} 1$, IgG2a and IgG2b and one in 1000 dilution for anti-rat IgA. Anti-rat IgG, IgG2a and IgG2b were obtained from Sigma and anti-rat IgG1, IgA and IgE were obtained from Serotec. Horseradish peroxidase-conjugated anti-rat IgG was quantified using Sigma Fast-OPD (Sigma) substrate with the reaction being stopped by the addition of $2 \cdot 5 \mathrm{M}-\mathrm{H}_{2} \mathrm{SO}_{4}$. Bound anti-rat IgE, IgG1, IgG2a and IgG2b was detected by the addition of a horseradish peroxidase-conjugated anti-mouse Ig antibody (Dako) at a dilution of one in 1000 before being quantified using Sigma Fast OPD as described previously. Antibody levels were expressed as the means of two optical density readings at $492 \mathrm{~nm}$.

\section{Calculations and statistical analysis}

Inspection of the raw data showed that five out of sixteen HP-Met rats refused approximately $75 \%$ of their already restricted allowances (four allocated to day 8 and one to day 11 endpoints). Such refusals are in agreement with other studies showing a reduced food intake that varies greatly between individual methionine-deficient foods ${ }^{(36-38)}$. In the present study, these were noted as soon as the food was offered, i.e. from day 0 onwards and before the secondary infection. In order to avoid bias arising from reduced food intake per se rather than from a methionine deficiency alone, the data from these five rats were omitted from all main analysis.

Data were analysed using restricted maximum likelihood, to account for differences in the achieved number of replicates per group, arising from the omission of five HP-Met rats with very high refusals and the a priori different replicates of infected and control dams for each feeding treatment. The factors used were feeding treatment (LP, HP, HP-Leu and HP-Met), infection pressure (secondary infection and sham control) and their two-way interaction on achieved feed intake, dam weight gain and litter weight gain including data from all animals until day 8 . The same factors were used for the analysis of inflammatory cells and antibody responses taken on day 8 from the infected and control dams. Restricted maximum likelihood was also used to assess the effects of feeding treatment, endpoint (days 8 and 11) and their twoway interaction on worm burdens, percentage of female worms, EIC, inflammatory cells and antibody responses. Contrast statements were used to locate three a priori-defined feeding treatment comparisons, i.e. HP $v$. HP-Leu, HP $v$. HPMet, and HP $v$. LP. Performance data are presented as arithmetic means, associated with standard errors or standard errors of the difference. However, because of their skewed nature, EIC, worm burdens, inflammatory cells and antibody responses were log-transformed $(n+1)$ to normalise variance before statistical analysis. These data are reported as backtransformed means with lower and upper limits of transformed standard errors. All statistical analyses were performed using Genstat 11 for Windows release 11.1, 2008 (VSN International).

\section{Results}

\section{Faecal egg counts and performance until parturition}

FEC taken on day -37 and day -30 averaged 8835 (79459825) and 0 (95\% CI 0, 0) eggs/g, respectively. Pre-mating FEC did not differ between the lactational treatment groups $(P=0 \cdot 511)$. Mean body weight on arrival was 374 (SE 6.8) g. During the first $10 \mathrm{~d}$ of gestation, pregnant rats grew from 387 (SE 6.4) to 425 (se 6.3) g and had an average DM intake of $21 \cdot 2(\operatorname{se~} 0 \cdot 40) \mathrm{g} / \mathrm{d}$. From then onwards and until parturition, the pregnant rats continued to grow to a mean weight of 512 (SE 5.7) $\mathrm{g}$ and had an average DM intake of 19.9 (SE 0.46) g/d, which dropped to an average of $7 \cdot 3$ (SE 2.0) g/d just before parturition. Mean dam PBW averaged 406 (SE 7.7) g, mean litter size averaged 14.4 pups (SE 0.39) and mean litter body weight averaged 76.6 (SE 1.8) g.

\section{Achieved DM intake, dam weight gain and litter weight gain}

Fig. 1 shows the effects of the feeding treatments on achieved mean DM intake (Fig. 1(a)), dam weight gain (Fig. 1(b)) and litter weight gain (Fig. 1(c)) in the infected and shaminfected control rats from parturition until day 8 of lactation. Achieved DM intake was not affected by feeding treatment $(P=0.65)$, infection $(P=0.22)$ or their interaction $(P=0.30$; Fig. 1(a)). Relative to the HP dams, the LP $(P<0 \cdot 001)$, HP-Leu $(P=0.05)$ and HP-Met dams $(P=0.001)$ had a lower mean body-weight gain, which was not affected by infection $(P=0.85)$, or the interaction between feeding treatment and infection $(P=0 \cdot 11$; Fig. 1(b)). Relative to the HP litters, the LP $(P=0.074)$ and HP-Leu litters $(P=0.085)$, but not the HP-Met litters $(P=0 \cdot 19)$ tended to have a lower weight gain, which was not affected by infection $(P=0.97)$, or the interaction between feeding treatment and infection $(P=0 \cdot 26$; Fig. 1(b)).

\section{Total worm burden, eggs in the colon and worm sex ratio}

Fig. 2(a)-(c) shows the effects of the feeding treatments on total worm burdens, EIC and worm burden composition for 

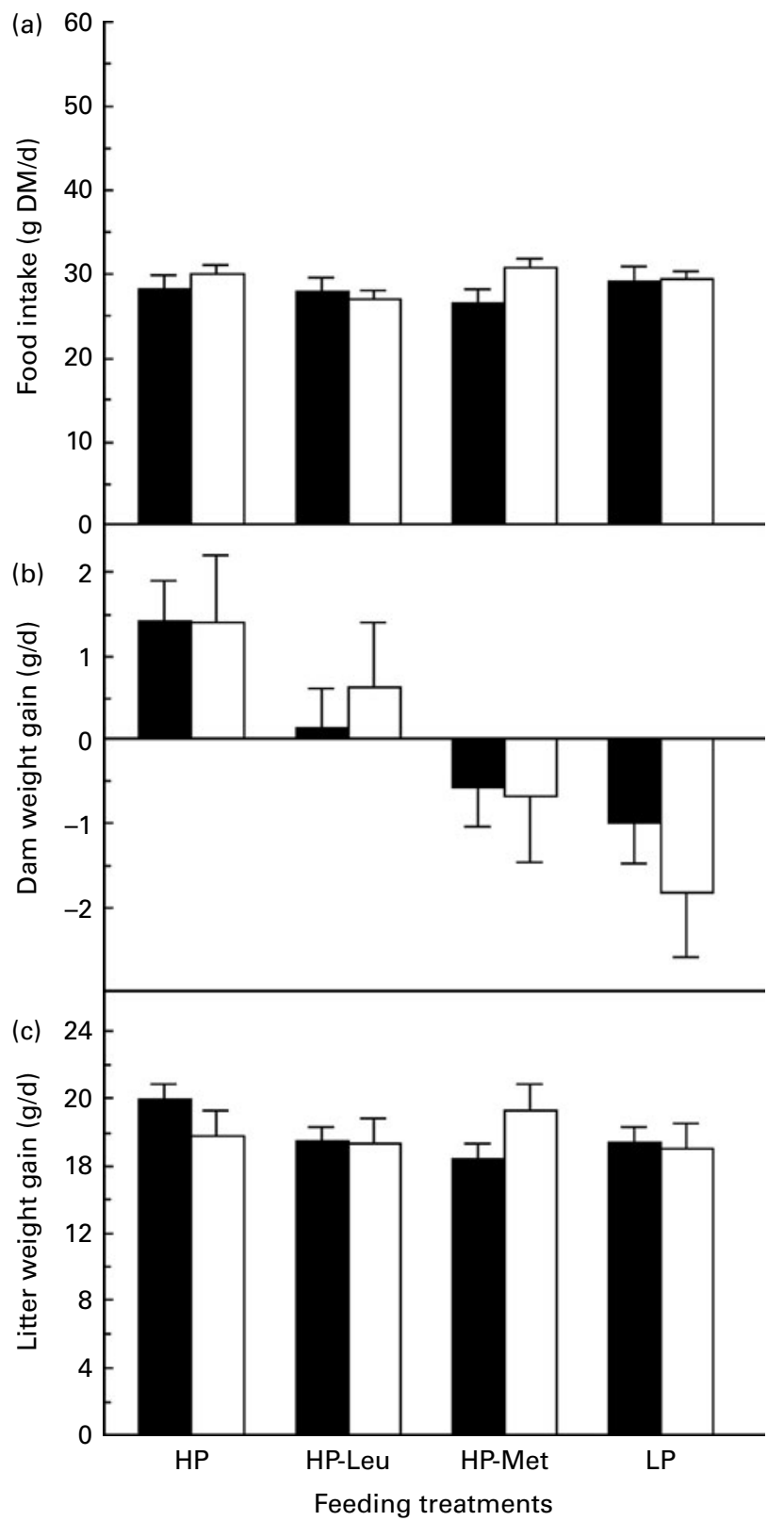

Fig. 1. (a) Average food intake, (b) dam weight gain and (c) litter weight gain for rats either reinfected $(\boldsymbol{\square})$ with Nippostrongylus brasiliensis or shaminfected $(\square)$ on day 2 of lactation and fed restricted amounts of a high-protein food (HP, $250 \mathrm{~g}$ crude protein (CP)/kg DM), low-protein food (LP, $150 \mathrm{~g}$ $\mathrm{CP} / \mathrm{kg} \mathrm{DM}$ ) or HP with similar levels of leucine (HP-Leu) or methionine (HP-Met) as in LP. Values are means, with their standard errors represented by vertical bars.

days 8 and 11 of lactation. Across the endpoints, the HP rats harboured fewer worms than the LP $(P<0 \cdot 001)$ and HP-Leu rats $(P=0.002)$ but not the HP-Met rats $(P=0.513$; Fig. 2(a)), while total worm burdens were not affected by endpoint $(P=0.431)$, and the interaction between feeding and endpoint $(P=0 \cdot 466)$. However, EIC was lower for the HP rats than for the LP $(P<0.001)$, HP-Leu $(P=0.001)$ and HP-Met rats $(P=0.011$; Fig. 2(b)), while, likewise, they were not affected by endpoint $(P=0.392)$ and the interaction between feeding treatment and endpoint $(P=0.588)$. The worm sex ratio
(Fig. 2(c)) was not affected by feeding treatment $(P=0.537)$ or the interaction between feeding treatment and endpoint ( $P=0 \cdot 149$ ), while the day 8 rats tended to harbour relatively fewer female worms than their day 11 counterparts $(P=0.068)$.

\section{Gut histopathology and systemic antibody levels}

Table 3 shows the effects of the feeding treatments on smallintestinal eosinophil, goblet cell and mucosal mast cell counts, respectively, in the sham-infected control rats (day 8) and infected rats (days 8 and 11). Eosinophil and mucosal mast cell numbers, but not globule leucocyte numbers, increased

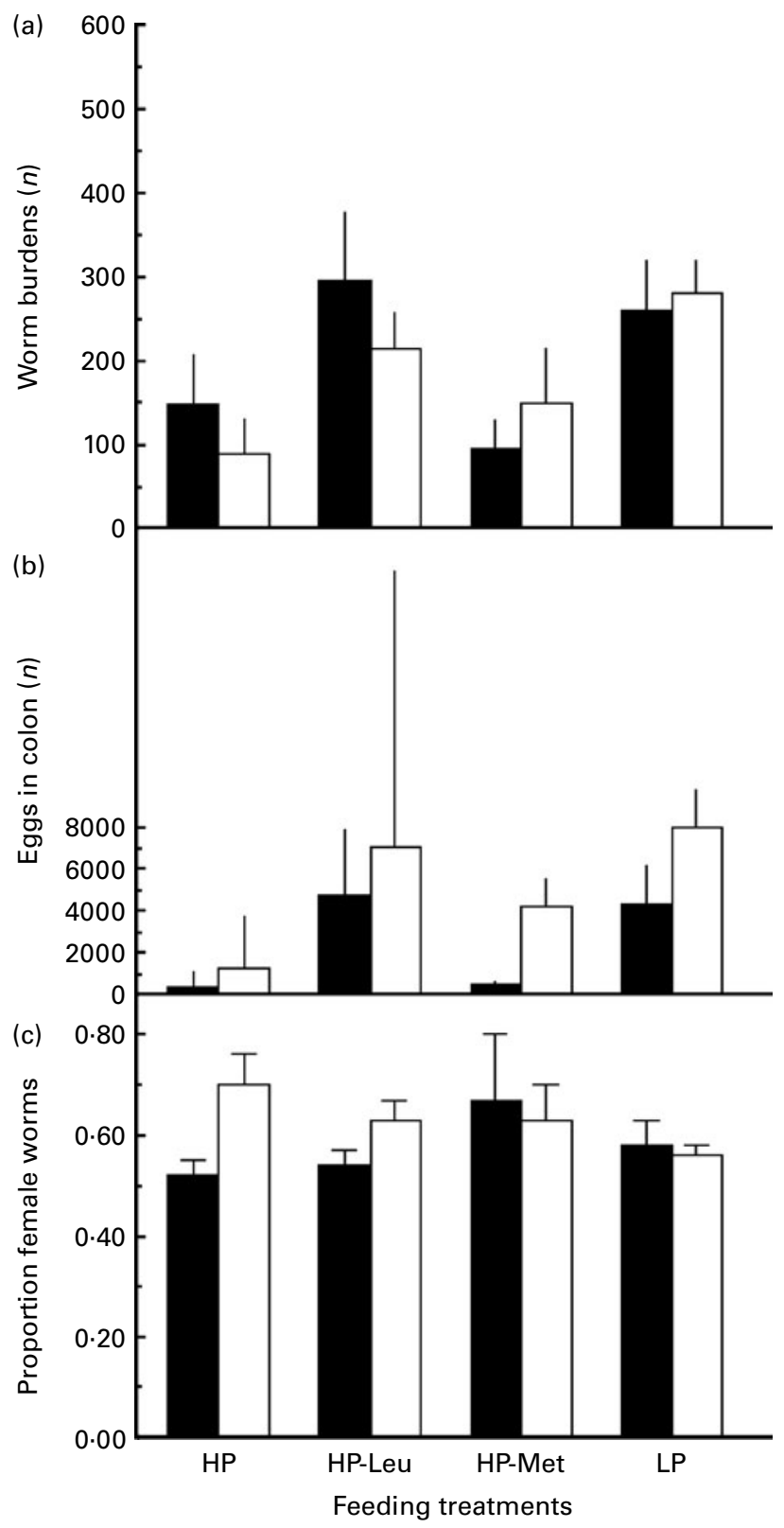

Fig. 2. (a) Backtransformed mean worm burdens, (b) backtransformed mean total eggs in the colon with backtransformed upper values of log-transformed mean with their standard errors and (c) percentage of female worms of lactating rats, reinfected with Nippostrongylus brasiliensis on day 2 of lactation and culled on either day 8 (ם). 
Table 3. Backtransformed mean number of small-intestinal mucosal inflammatory cells (number per villus crypt unit), with backtransformed range*, of rats reinfected with Nippostrongylus brasiliensis or sham-infected on day 2 of lactation and fed restricted amounts of a high-protein food (HP, $250 \mathrm{~g}$ crude protein (CP)/ $\mathrm{kg} \mathrm{DM}$ ), low-protein food (LP, $150 \mathrm{~g} \mathrm{CP} / \mathrm{kg} \mathrm{DM}$ ) or HP with similar levels of leucine (HP-Leu) or methionine (HP-Met) as in LP

(Mean values with their ranges)

\begin{tabular}{|c|c|c|c|c|c|c|c|c|c|}
\hline \multirow[b]{2}{*}{ Days } & \multirow[b]{2}{*}{ Infection } & \multirow[b]{2}{*}{ Diets } & \multirow[b]{2}{*}{$n \dagger$} & \multicolumn{2}{|c|}{ Eosinophils } & \multicolumn{2}{|c|}{ Goblet cells } & \multicolumn{2}{|c|}{ Mast cells } \\
\hline & & & & Mean & Range & Mean & Range & Mean & Range \\
\hline \multirow[t]{4}{*}{8} & \multirow[t]{4}{*}{ Sham } & HP & 4 & 19 & $18-21$ & 34 & $31-38$ & 19 & $17-22$ \\
\hline & & LP & 4 & 25 & $23-28$ & 46 & $42-50$ & 18 & $17-20$ \\
\hline & & HP-Leu & 4 & 18 & $14-24$ & 41 & $30-55$ & 22 & $20-24$ \\
\hline & & HP-Met & 5 & 22 & $17-29$ & 50 & $42-59$ & 21 & $20-22$ \\
\hline \multirow[t]{4}{*}{8} & \multirow[t]{4}{*}{ N. brasiliensis } & $\mathrm{HP}$ & 5 & 49 & $43-56$ & 40 & $34-46$ & 30 & $27-33$ \\
\hline & & LP & 5 & 31 & $24-40$ & 51 & $43-61$ & 25 & $21-29$ \\
\hline & & HP-Leu & 5 & 31 & $26-38$ & 50 & $44-57$ & 26 & $25-28$ \\
\hline & & HP-Met & 2 & 22 & $14-35$ & 53 & - & 25 & $17-36$ \\
\hline \multirow[t]{4}{*}{11} & \multirow[t]{4}{*}{ N. brasiliensis } & $\mathrm{HP}$ & 6 & 78 & $67-92$ & 42 & $35-49$ & 46 & $40-54$ \\
\hline & & LP & 5 & 60 & $45-80$ & 42 & $37-47$ & 48 & $43-54$ \\
\hline & & HP-Leu & 5 & 70 & $60-82$ & 43 & $37-49$ & 47 & $42-52$ \\
\hline & & HP-Met & 4 & 65 & $57-74$ & 47 & $42-52$ & 44 & $37-54$ \\
\hline \multicolumn{10}{|l|}{$P$ of effects } \\
\hline \multirow[t]{3}{*}{ Diet $\times$ infection $\ddagger$} & \multicolumn{3}{|l|}{ Diet } & \multicolumn{2}{|c|}{0.210} & \multicolumn{2}{|c|}{0.381} & \multicolumn{2}{|c|}{0.564} \\
\hline & \multicolumn{3}{|l|}{ Infection } & \multicolumn{2}{|c|}{0.010} & \multicolumn{2}{|c|}{0.272} & \multicolumn{2}{|c|}{0.004} \\
\hline & \multicolumn{3}{|l|}{ Diet $\times$ infection } & \multicolumn{2}{|c|}{0.194} & \multicolumn{2}{|c|}{0.961} & \multicolumn{2}{|c|}{0.670} \\
\hline \multirow[t]{3}{*}{ Diet $\times$ day§ } & \multicolumn{3}{|l|}{ Diet } & \multirow{2}{*}{\multicolumn{2}{|c|}{$\begin{array}{l}0.159 \\
0.001\end{array}$}} & \multicolumn{2}{|c|}{0.681} & \multicolumn{2}{|c|}{0.937} \\
\hline & \multicolumn{3}{|l|}{ Day } & & & & & & \\
\hline & Diet $x$ day & & & \multicolumn{2}{|c|}{0.498} & & & & \\
\hline
\end{tabular}

*Backtransformed values of log-transformed mean values with their standard errors.

† Number of replicates; data from five HP-Met rats were omitted due to high levels of refusals (four from day 8 and one from day 11). $\ddagger$ Using data from sham and infected rats on endpoint day 8 of lactation only.

$\S$ Using data from endpoints day 8 and day 11 of lactation from infected rats only.

with infection and with time, but none was affected by the feeding treatments. Tables 4 and 5 show the effects of the feeding treatments on the serum levels of $N$. brasiliensisspecific total IgG, IgA and IgE (Table 4), and IgG1, IgG2a and IgG2b (Table 5) in the sham-infected control rats (day 8 ) and infected rats (days 8 and 11). Infection significantly increased the serum levels of all antibodies assessed $(P<0 \cdot 001)$, but there were no significant effects of feeding treatment or interactions between feeding treatment and infection. Feeding treatment and endpoint tended to interact for $\operatorname{IgE}(P=0.063)$, as IgE levels were lower in the HP-Met rats compared with the other feeding treatment groups on day 11 only. Feeding treatment, endpoint and their interaction did not significantly affect the levels of any other isotypes measured.

\section{Discussion}

Previous studies carried out with this rodent-nematode parasite model have shown that feeding low-CP foods results in higher worm burdens, egg excretion, increased proportion of female worms and reduced immune responses compared with feeding high-CP foods ${ }^{(4-7)}$. Here we hypothesised that a reduced availability of either all AA (LP) or of the essential AA leucine or methionine would result in penalties on both lactational performance and the expression of immunity to parasites, thus resulting in higher worm burdens. Our null hypothesis was that the magnitude of these effects would be similar between the two AA considered, as a single essential AA deficiency could have an impact on all (essential)
AA utilisation, especially if the AA is rate limiting ${ }^{(19,39)}$. We demonstrated that dietary scarcity of all AA (LP) or of either methionine or leucine indeed reduced lactational performance and increased parasitism in the infected host. However, in contrast to our earlier findings ${ }^{(6)}$, these observed effects did not appear to be related to changes in mucosal immune cell populations or serum antibody levels, which were largely unaffected by our feeding treatments. The effects observed of our EAAdeficient foods are discussed below in relation to their reduced supply for the activation and maintenance of the host's bodily functions associated with the expression of immunity to $N$. brasiliensis and lactational performance.

Parasitic infection leads to increased protein requirements of immune hosts, mainly in order to activate, or maintain, an effective protective response, but also to repair and replace damaged tissue arising from immunopathological responses ${ }^{(9)}$. Effector molecules of the immune response are highly proteinaceous, and inflammation and immune system activation are characterised by the synthesis of specific proteins that play crucial roles in the defence of the host against pathogens and modulation of the ongoing immune response $^{(12,40)}$. In addition, lactation also increases protein requirements, as a consequence of increased AA uptake into the mammary gland ${ }^{(22,24)}$. In our experimental design, these effects were expected to be even more pronounced due to the depleted state of the labile protein reserves as a result of the consumption of a low-CP food during the second half of gestation $^{(32)}$.

As in our previous experiment ${ }^{(7)}$, restricted feeding of LP foods to lactating parasitised hosts resulted in protein scarcity. 
Table 4. Backtransformed mean levels of total serum $\operatorname{lgG}$, $\lg A$ and $\lg E$, with backtransformed range ${ }^{\star}$, of rats reinfected with Nippostrongylus brasiliensis or sham-infected on day 2 of lactation and fed restricted amounts of a high-protein food (HP, $250 \mathrm{~g}$ crude protein (CP)/kg DM), low-protein food (LP, $150 \mathrm{~g} \mathrm{CP} / \mathrm{kg} \mathrm{DM}$ ) or HP with similar levels of leucine (HP-Leu) or methionine (HP-Met) as in LP (Mean values with their ranges)

\begin{tabular}{|c|c|c|c|c|c|c|c|c|c|}
\hline \multirow[b]{2}{*}{ Days } & \multirow[b]{2}{*}{ Infection } & \multirow[b]{2}{*}{ Diets } & \multirow[b]{2}{*}{$n \dagger$} & \multicolumn{2}{|c|}{ Total IgG } & \multicolumn{2}{|r|}{$\lg A$} & \multicolumn{2}{|r|}{$\lg \mathrm{E}$} \\
\hline & & & & Mean & Range & Mean & Range & Mean & Range \\
\hline \multirow[t]{4}{*}{8} & \multirow[t]{4}{*}{ Sham } & HP & 4 & 0.17 & $0.13-0.23$ & 0.14 & $0.09-0.20$ & $0 \cdot 16$ & $0.12-0.21$ \\
\hline & & LP & 4 & $0 \cdot 10$ & $0.07-0.14$ & 0.10 & $0.07-0.14$ & 0.11 & $0.08-0.16$ \\
\hline & & HP-Leu & 4 & 0.15 & $0.11-0.21$ & 0.14 & $0.10-0.19$ & 0.16 & $0.13-0.31$ \\
\hline & & HP-Met & 5 & 0.18 & $0.14-0.23$ & 0.12 & $0.10-0.15$ & 0.13 & $0.12-0.16$ \\
\hline \multirow[t]{4}{*}{8} & \multirow[t]{4}{*}{ N. brasiliensis } & $\mathrm{HP}$ & 5 & 0.36 & $0.31-0.42$ & 0.53 & $0.45-0.62$ & 0.54 & $0.46-0.65$ \\
\hline & & LP & 5 & 0.39 & $0.36-0.42$ & 0.68 & $0.59-0.78$ & 0.68 & $0.58-0.79$ \\
\hline & & HP-Leu & 5 & 0.47 & $0.42-0.52$ & 0.69 & $0.61-0.78$ & 0.76 & $0.71-0.80$ \\
\hline & & HP-Met & 2 & 0.43 & $0.38-0.47$ & 0.57 & $0.52-0.63$ & 0.76 & $0.71-0.80$ \\
\hline \multirow[t]{4}{*}{11} & \multirow[t]{4}{*}{ N. brasiliensis } & $\mathrm{HP}$ & 6 & 0.38 & $0.34-0.42$ & 0.65 & $0.58-0.72$ & 0.71 & $0.63-0.79$ \\
\hline & & LP & 5 & 0.52 & $0.46-0.58$ & 0.70 & $0.62-0.79$ & 0.80 & $0.69-0.93$ \\
\hline & & HP-Leu & 5 & 0.39 & $0.32-0.47$ & 0.52 & $0.44-0.61$ & 0.61 & $0.52-0.73$ \\
\hline & & HP-Met & 4 & 0.28 & $0.24-0.34$ & 0.42 & $0.39-0.46$ & 0.44 & $0.41-0.48$ \\
\hline \multicolumn{10}{|l|}{$P$ of effects } \\
\hline \multirow[t]{3}{*}{ Diet $\times$ infection $\ddagger$} & \multicolumn{3}{|l|}{ Diet } & \multicolumn{2}{|r|}{0.517} & \multicolumn{2}{|r|}{$0 \cdot 166$} & \multicolumn{2}{|r|}{0.140} \\
\hline & \multicolumn{3}{|l|}{ Infection } & \multicolumn{2}{|r|}{0.001} & \multicolumn{2}{|r|}{0.001} & \multicolumn{2}{|r|}{0.001} \\
\hline & \multicolumn{3}{|l|}{ Diet $\times$ infection } & \multicolumn{2}{|r|}{0.436} & \multicolumn{2}{|r|}{0.685} & \multicolumn{2}{|r|}{0.512} \\
\hline \multirow[t]{3}{*}{ Diet $\times$ day§ } & \multicolumn{3}{|l|}{ Diet } & \multicolumn{2}{|r|}{0.138} & \multicolumn{2}{|r|}{0.126} & \multicolumn{2}{|r|}{0.272} \\
\hline & \multirow{2}{*}{\multicolumn{3}{|c|}{$\begin{array}{l}\text { Day } \\
\text { Diet } \times \text { day }\end{array}$}} & \multicolumn{2}{|r|}{$0 \cdot 805$} & & 0.555 & & $0 \cdot 869$ \\
\hline & Diet $\times$ day & & & & 0.116 & & 0.195 & & 0.063 \\
\hline
\end{tabular}

*Backtransformed values of log-transformed mean with their standard errors.

† Number of replicates; data from five HP-Met rats were omitted due to high levels of refusals (four from day 8 and one from day 11). ¥Using data from sham and infected rats on endpoint day 8 of lactation only.

$\S$ Using data from endpoints day 8 and day 11 of lactation from infected rats only.

The penalties of protein scarcity were evident from a reduced lactational performance (both lower dam weight gain and, to a lesser extent, litter weight gain) and higher levels of parasitism (worm burdens and EIC) in LP rats compared with HP rats. The more pronounced effects on dam weight gain compared with litter weight gain suggest that dams may mobilise body protein reserves to minimise the penalties of dietary protein scarcity on milk production ${ }^{(41)}$. In previous studies, and in contrast to the present results, the effects of $\mathrm{CP}$ supply on parasitological measurements have concurred with the effects

Table 5. Backtransformed mean levels of serum IgG1, IgG2a and IgG2b, with backtransformed range ${ }^{*}$, of rats reinfected with Nippostrongylus brasiliensis or sham-infected on day 2 of lactation and fed restricted amounts of a high-protein food (HP, $250 \mathrm{~g}$ crude protein (CP)/kg DM), low-protein food (LP, $150 \mathrm{~g} \mathrm{CP/kg} \mathrm{DM)} \mathrm{or} \mathrm{HP} \mathrm{with} \mathrm{similar} \mathrm{levels} \mathrm{of} \mathrm{leucine} \mathrm{(HP-Leu)} \mathrm{or} \mathrm{methionine} \mathrm{(HP-Met)} \mathrm{as} \mathrm{in} \mathrm{LP}$ (Mean values with their ranges)

\begin{tabular}{|c|c|c|c|c|c|c|c|c|c|}
\hline \multirow[b]{2}{*}{ Days } & \multirow[b]{2}{*}{ Infection } & \multirow[b]{2}{*}{ Diets } & \multirow[b]{2}{*}{$n \dagger$} & \multicolumn{2}{|c|}{ Total IgG } & \multicolumn{2}{|r|}{$\lg A$} & \multicolumn{2}{|r|}{$\lg \mathrm{E}$} \\
\hline & & & & Mean & Range & Mean & Range & Mean & Range \\
\hline \multirow[t]{4}{*}{8} & \multirow[t]{4}{*}{ Sham } & $\mathrm{HP}$ & 4 & 0.09 & $0.07-0.13$ & 0.28 & $0.20-0.38$ & $0 \cdot 16$ & $0.08-0.18$ \\
\hline & & LP & 4 & 0.07 & $0.05-0.10$ & 0.14 & $0.09-0.23$ & 0.12 & $0.08-0.18$ \\
\hline & & HP-Leu & 4 & $0 \cdot 10$ & $0.08-0.13$ & 0.24 & $0.16-0.38$ & 0.20 & $0.16-0.27$ \\
\hline & & HP-Met & 5 & 0.09 & $0.07-0.10$ & 0.26 & $0.21-0.33$ & 0.14 & $0.12-0.17$ \\
\hline \multirow[t]{4}{*}{8} & \multirow[t]{4}{*}{ N. brasiliensis } & $\mathrm{HP}$ & 5 & 0.35 & $0.30-0.41$ & 0.61 & $0.51-0.74$ & 0.54 & $0.44-0.65$ \\
\hline & & LP & 5 & 0.46 & $0.41-0.52$ & 0.78 & $0.71-0.85$ & 0.67 & $0.62-0.73$ \\
\hline & & HP-Leu & 5 & 0.46 & $0.41-0.51$ & 0.92 & $0.78-1.09$ & 0.72 & $0.61-0.85$ \\
\hline & & HP-Met & 2 & 0.45 & $0.42-0.48$ & 0.89 & $0.69-1.15$ & 0.63 & $0.61-0.66$ \\
\hline \multirow[t]{4}{*}{11} & \multirow[t]{4}{*}{ N. brasiliensis } & $\mathrm{HP}$ & 6 & 0.44 & $0.39-0.50$ & 0.79 & $0.70-0.90$ & 0.63 & $0.56-0.71$ \\
\hline & & LP & 5 & 0.50 & $0.44-0.56$ & 1.04 & $0.90-1 \cdot 21$ & 0.81 & $0.61-1.01$ \\
\hline & & HP-Leu & 5 & 0.40 & $0.32-0.51$ & 0.75 & $0.61-0.92$ & 0.58 & $0.48-0.70$ \\
\hline & & HP-Met & 4 & 0.28 & $0.27-0.30$ & 0.52 & $0.46-0.59$ & 0.40 & $0.38-0.42$ \\
\hline \multicolumn{10}{|l|}{$P$ of effects } \\
\hline \multirow[t]{3}{*}{ Diet $\times$ infection $\ddagger$} & \multicolumn{3}{|l|}{ Diet } & \multicolumn{2}{|r|}{0.181} & \multicolumn{2}{|r|}{0.629} & \multicolumn{2}{|r|}{0.113} \\
\hline & \multicolumn{3}{|l|}{ Infection } & \multicolumn{2}{|r|}{0.001} & \multicolumn{2}{|r|}{0.001} & \multicolumn{2}{|r|}{0.001} \\
\hline & \multicolumn{3}{|l|}{ Diet $\times$ infection } & \multicolumn{2}{|r|}{0.514} & \multicolumn{2}{|r|}{0.304} & \multicolumn{2}{|r|}{0.552} \\
\hline \multirow[t]{3}{*}{ Diet $\times$ day§ } & \multicolumn{3}{|l|}{ Diet } & \multirow{2}{*}{\multicolumn{2}{|c|}{$0 \cdot 192$}} & \multirow{2}{*}{\multicolumn{2}{|c|}{$0 \cdot 180$}} & \multicolumn{2}{|r|}{0.152} \\
\hline & \multicolumn{3}{|l|}{ Day } & & & & & & 0.768 \\
\hline & Diet $\times$ day & & & & 0.197 & & 0.091 & & 0.259 \\
\hline
\end{tabular}

*Backtransformed values of log-transformed mean with their standard errors.

† Number of replicates; data from five HP-Met rats were omitted due to high levels of refusals (four from day 8 and one from day 11).

¥Using data from sham and infected rats on endpoint day 8 of lactation only.

$\S$ Using data from endpoints day 8 and day 11 of lactation from infected rats only. 
on the number of inflammatory cells in the intestinal epithelium, such as mucosal mast cells, goblet cells and eosinophils, and local and circulating antibody responses ${ }^{(5,6)}$. It should be noted that our previous studies were designed to induce a higher degree of protein scarcity than the one imposed in the present study, achieving CP supply during lactation as low as $6.6 \mathrm{~g} / \mathrm{d}$ per $\mathrm{kg} \mathrm{PBW}^{(5,6)}$ as opposed to $13.3 \mathrm{~g} / \mathrm{d}$ per kg PBW offered in the present experiment. Here, we deliberately chose to use a less severe level of $\mathrm{CP}$ scarcity in order to minimise the possible effect of AA imbalance per se for the essential AA-deficient foods. Consequently, the body-weight loss observed (Fig. 1) may have mobilised sufficient AA from body protein reserves to meet AA requirement for producing the elevated levels of inflammatory cells and Ig upon infection (Tables 3 and 4). However, it is also well known that parasite expulsion is mediated by a range of effector molecules $^{(42,43)}$ and that not a single mechanism is responsible for the expulsion of the parasite population. Therefore, it cannot be excluded that our feeding treatments may have affected other than the measured immunological responses.

The present data showed that HP-Leu feeding penalised litter and dam weight gain relative to $\mathrm{HP}$ feeding. The uptake of AA from the mammary gland usually exceeds their quantitative excretion in milk, especially for leucine, in many mammalian species including pigs, goats and rats $^{(22,23,44)}$. A decrease in leucine blood concentration occurs during lactation ${ }^{(24)}$ when enzymes that are associated with its catabolism are induced in the mammary gland ${ }^{(45)}$, directing it for the synthesis of glutamine and glutamate ${ }^{(46)}$, which are abundant AA in milk proteins ${ }^{(47)}$. Additionally, the excess net uptake of leucine by the mammary gland is further enhanced by dietary protein supplementation ${ }^{(44)}$. As a consequence, one would expect that leucine deficiency would lead to a penalised pup performance arising from the reduced supply of leucine to the mammary gland and/or an increased mobilisation of body protein tissue ${ }^{(48)}$, which would be reflected in the dam body-weight gain.

Despite the relatively small effect of leucine deficiency on lactational performance as reflected in dam and litter weight gain, HP-Leu dams had significantly higher worm burdens and EIC compared with HP dams, which was not associated with differences in any of the immune measurements taken. The parasitological data indicate that the penalties induced on resistance were higher in comparison with the lactational performance under leucine deficiency. This is in agreement with the suggestion that immunity to parasites is given a lower priority than reproductive functions in periparturient hosts when nutrients are scarce ${ }^{(8)}$. The absence of an effect on the immune parameters measured is contrary to the expectation, as cell-culture and animal feeding studies show a dose-response between leucine supply and the immune response to pathogens ${ }^{(10)}$. Leucine is the sole branchedchain AA that can activate the mTOR pathway in intestinal epithelial cells ${ }^{(49)}$, and it may play an important role in intestinal repair via stimulation of protein growth $^{(50)}$. A damaged mucosa could be associated with the higher number of worm burdens in our HP-Leu dams. Although the number of inflammatory cells in the intestinal mucosa, such as mast cells and eosinophils that are partly responsible for wound repair, did not appear to be affected by the feeding treatment, differential protein or gene expression in these cells cannot be excluded.

The present data showed that HP-Met feeding penalised dam weight gain but not litter weight gain relative to HP feeding. The importance of methionine supply in lactating rats has long been recognised ${ }^{(51)}$, and improved dam weight gain during lactation has been observed upon methionine supplementation in both low- and high-casein diets ${ }^{(52)}$. Substantial body-weight loss of approximately $44 \%$ has also been observed in non-lactating adult rats fed methionine-restricted foods ${ }^{(36)}$. The absence of the effects on litter weight gain but also on worm burdens in the presence of body-weight loss suggests that the aforementioned mobilisation of body protein reserves may have supplied sufficient methonine to overcome the penalties of dietary methione scarcity on milk production and resistance. While this seems to contrast with earlier observations, where methionine supplementation of casein-based foods resulted in reduced $N$. brasiliensis worm burdens in growing rats ${ }^{(30)}$, it should be noted that, in line with our observations on the intake of the HP-Met food, these results could have arisen from an increased food intake per se. Indeed, casein is limiting in $\mathrm{SAA}^{(33)}$, and it is for this reason that we consistently supplement casein with methionine to study the effect of CP supply on lactational resistance to parasites in the $N$. brasiliensis re-infection lactating rat model $^{(4-7,31)}$. The discrepancy between the effect of HP-Met on worm burdens and the number of worm EIC could suggest that low dietary methionine supply affects nematode fecundity. It has indeed been observed that worm egg excretion may be more sensitive to protein scarcity than worm expulsion $^{(2)}$.

We omitted approximately $45 \%$ of the HP-Met rats from the main data analysis, as they showed very high refusals, in order to avoid confounding effects of methionine supply with feed intake per se. An additional restricted maximum-likelihood analysis on the parameters measured supports the view that this was warranted. Compared with their counterparts, the infected HP-Met animals showing high refusals had lower DM intake (26.4 v. $7.1 \mathrm{~g} / \mathrm{d} ;$ SED $2.50 \mathrm{~g} / \mathrm{d} ; \quad P<0.001)$, dam weight gain $(-0.58 v .-9.02 \mathrm{~g} / \mathrm{d}$; SED $0.977 ; P<0.001)$ and litter weight gain $(16.5 v .3 .1 \mathrm{~g} / \mathrm{d}$; SED $1.66 ; P<0.001)$. In addition, they carried higher worm burdens (127 (98-165) $v$. 409 (307-545); $P=0.015)$ and their eosinophil numbers were lower (48 (36-64) v. 20 (12-35) cells/villus crypt unit; $P=0.089)$. The latter observation support the aforementioned view that the absence of the effects of CP scarcity on inflammatory cells in the main dataset was probably the outcome of using a less severe level of CP scarcity than used in our earlier studies. While the number of eggs in the colon, mast cells and goblet cells of HP-Met refusers were similar to those in their counterparts, their Ig levels were significantly elevated by $39-51 \%(P<0.05)$. Although it cannot be excluded that the latter had partly arisen from a reduced blood volume arising from the severely reduced food intake, this further suggests that serum immunoglobulins are unlikely to play a direct role in worm expulsion from the gastrointestinal tract ${ }^{(6)}$. 
In conclusion, leucine and methionine deficiency in a highprotein food penalised lactating host resistance to a secondary infection with gastrointestinal nematodes and reduced lactational performance. From the immune indicators measured in the present study, which have previously been associated with the immunomodulatory effects of dietary protein, none was significantly affected. Consequently, further studies to elucidate the underlying mechanisms of reduced resistance following leucine and methionine scarcity should concentrate on other indicators of immunity. In light of the role of AA as immunonutrients and the strong effect that protein supply has on the periparturient host resistance to gastrointestinal nematodes, more AA could be tested using the model established here, including at different dietary levels so as to minimise the consequences of AA imbalance per se. The present results imply that AA balance and thus protein quality should be important considerations in immunonutrition strategies for livestock animals, in which periparturient breakdown of immunity to parasites causes significant economic losses.

\section{Acknowledgements}

The authors wish to thank the staff of the March Building at the University of Edinburgh for animal husbandry, Ian Nevison (Biomathematics and Statistics Scotland) for statistical advice and Meike Rademacher (Evonik, Germany) for the AA analyses of the experimental foods. This study was supported by the Biotechnology and Biology Sciences Research Council (BBSRC). The Scottish Agricultural College and the Moredun Research Institute receive support from the Scottish Government, Rural and Environmental Research and Analysis Directorate. P. S. is grateful to the Hellenic State Scholarship Foundation for the provision of a postgraduate scholarship. None of the authors has a conflict of interest in relation to this study. This study has resulted from the postgraduate studies of P. S. and is part of his PhD thesis. P. S. and L. A. J. are joint first authors. P. S., L. A. J., J. G. M. H., S. A., D. P. K. and I. K. conceived and designed the experiment. P. S. and L. A. J. performed the experiment. D. P. K. provided the infective larvae and facilities for the immunological analysis. P. S., L. A. J. and J. G. M. H. analysed the data. P. S., L. A. J., J. G. M. H., S. A., D. P. K. and I. K. contributed to data interpretation and manuscript preparation.

\section{References}

1. Donaldson J, Van Houtert MFJ \& Sykes AR (1998) The effect of nutrition on the periparturient parasite status of mature ewes. Anim Sci 67, 523-533.

2. Houdijk JGM, Kyriazakis I, Jackson F, et al. (2003) Is the allocation of metabolisable protein prioritised to milk production rather than to immune functions in Teladorsagia circumcincta-infected lactating ewes? Int J Parasitol 33, 327-338.

3. Chartier C, Etter E, Hoste H, et al. (2000) Effects of the initial level of milk production and of the dietary protein intake on the course of natural nematode infection in dairy goats. Vet Parasitol 92, 1-13.
4. Houdijk JGM, Jessop NS, Knox DP, et al. (2005) Secondary infection of Nippostrongylus brasiliensis in lactating rats is sensitive to dietary protein content. Br J Nutr 93, 493-499.

5. Jones LA, Houdijk JGM, Knox DP, et al. (2009) Immunomodulatory effects of dietary protein during Nippostrongylus brasiliensis re-infection in lactating rats. Parasite Immunol 31, 412-421.

6. Jones LA, Houdijk JGM, Sakkas P, et al. (2011) Dissecting the impact of protein versus energy host nutrition on the expression of immunity to gastrointestinal parasites during lactation. Int J Parasitol 41, 711-719.

7. Sakkas P, Houdijk JGM, Jones LA, et al. (2011) Dietary protein and energy supplies differentially affect resistance to parasites in lactating mammals. Br J Nutr 106, 1207-1215.

8. Coop RL \& Kyriazakis I (1999) Nutrition-parasite interaction. Vet Parasitol 84, 187-204.

9. Kyriazakis I \& Houdijk JGM (2006) Immunonutrition: nutritional control of parasites. Small Rumin Res 62, 79-82.

10. Calder PC (2006) Branched-chain amino acid and immunity. J Nutr 136, 288S-293S.

11. Kim SW, Mateo RD, Yin YL, et al. (2007) Functional amino acids and fatty acids for enhancing production performance of sows and piglets. Asian Aust J Anim Sci 20, 295-306.

12. Le Floc'h N, Melchior D \& Obled C (2004) Modifications of protein and amino acid metabolism during inflammation and immune system activation. Livest Prod Sci 87, 37-45.

13. Clowes EJ, Aherne FX \& Baracos VE (2005) Skeletal muscle protein mobilization during the progression of lactation. $\mathrm{Am}$ J Physiol Endocrinol Metab 288, 564-572.

14. Stoll B, Henry J, Reeds PJ, et al. (1998) Catabolism dominates the firstpass intestinal metabolism of dietary essential amino acids in milk protein-fed piglets. J Nutr 128, 606-614.

15. Wu G (1998) Intestinal mucosal amino acid catabolism. J Nutr 128, 1249-1252.

16. Wang WW, Qiao SY \& Li DF (2009) Amino acids and gut function. Amino Acids 37, 105-110.

17. Wu G (2009) Amino acids: metabolism, functions, and nutrition. Amino Acids 37, 1-17.

18. Gietzen DW, Hao S \& Anthony TG (2007) Mechanisms of food intake repression in indispensable amino acid deficiency. Annu Rev Nutr 27, 63-78.

19. D'Mello JFP (2003) Amino acids as multifunctional molecules. In Amino Acids in Animal Nutrition, 2nd ed., pp. 1-14 [JPF D'Mello, editor]. Cambridge, MA: CABI Publishing.

20. Li P, Yin YL, Li D, et al. (2007) Amino acids and immune function. Br J Nutr 98, 237-252.

21. Yu F, Bruce LA, Calder AG, et al. (2000) Subclinical infection with the nematode Trichostrongylus colubriformis increases gastrointestinal tract leucine metabolism and reduces availability of leucine for other tissues. J Anim Sci 78, 380-390.

22. Trottier NL, Shipley CF \& Easter RA (1997) Plasma amino acid uptake by the mammary gland of the lactating sow. J Anim Sci 75, 1266-1278.

23. DeSantiago S, Torres N \& Tovar AR (1998) Leucine catabolism in mammary tissue, liver and skeletal muscle of dam rat during lactation and weaning. Arch Med Res 29, 25-32.

24. Vina JR \& Williamson DH (1981) Effects of lactation on L-leucine metabolism in the rat. Biochem J 194, 941-947.

25. Grimble RF (2006) The effects of sulfur amino acid intake on immune function in humans. J Nutr 136, 1660S-1665S.

26. Fang Z, Yao K, Zhang X, et al. (2010) Nutrition and health relevant regulation of intestinal sulfur amino acid metabolism. Amino Acids 39, 633-640.

27. Hoskin SO, Lobley GE, Coop RL, et al. (2002) The effect of cysteine and glutamine supplementation on sheep infected 
with Trichostrongylus colubriformis. Proc N Z Soc Anim Prod 62, 72-76.

28. Liu SM, Smith TL, Briegel J, et al. (2007) Fractional protein synthesis rate and polyamine concentrations in tissues of Merino sheep selected for gastrointestinal nematode resistance. Livest Sci 106, 65-75.

29. Poppi DP, MacRae JC, Brewer A, et al. (1986) Nitrogen transactions in the digestive tract of lambs exposed to the intestinal parasite Trichostrongylus colubriformis. Br J Nutr 55 , 593-602.

30. Cummins AG, Bolin TD, Duncombe VM, et al. (1986) The effect of methionine and protein deficiency in delaying expulsion of Nippostrongylus brasiliensis in the rat. Am J Clin Nutr 44, 857-862.

31. Houdijk JGM, Jessop NS, Knox DP, et al. (2003) Breakdown of immunity to Nippostrongylus brasiliensis in lactating rats. Br J Nutr 90, 809-814.

32. Pine AP, Jessop NS \& Oldham JD (1994) Maternal protein reserves and their influence on lactational performance in rats. Br J Nutr 71, 13-27.

33. DeMan JM (1999) Principles of Food Chemistry, 3rd ed., pp. 111-162. Frederick, MD: Aspen Publishers.

34. Christie M \& Jackson F (1982) Specific identification of strongyle eggs in small samples of sheep faeces. Res Vet Sci 32, $113-117$.

35. Ball G, Selkirk ME \& Knox DP (2007) The effect of vaccination with a recombinant Nippostrongylus brasiliensis acetylcholinesterase on infection outcome in the rat. Vaccine 25, 3365-3372.

36. Elshorbagy AK, Valdivia-Garcia M, Refsum H, et al. (2010) Sulfur amino acids in methionine restricted rats: hyperhomocysteinemia. Nutrition 26, 1201-1204.

37. Miller RA, Buehner G, Chang Y, et al. (2005) Methioninedeficient diet extends mouse lifespan, slows immune and lens aging, alters glucose, T4, IGF-I and insulin levels, and increases hepatocyte MIF levels and stress resistance. Aging Cell 4, 119-125.

38. Nkabyo YS, Gu LH, Jones DP, et al. (2006) Thiol/disulfide redox status is oxidized in plasma and small intestinal and colonic mucosa of rats with inadequate sulfur amino acid intake. J Nutr 136, 1242-1248.

39. McDonald P, Edwards RA, Greenhalgh JFD, et al. (2002) Animal Nutrition, 6th ed. Harlow: Pearson Education Limited.

40. Coop RL \& Kyriazakis I (2001) Influence of host nutrition on the development and consequences of nematode parasitism in ruminants. Trends Parasitol 17, 325-330.
41. Houdijk JGM, Jessop NS \& Kyriazakis I (2001) Nutrient partitioning between reproductive and immune functions in animals. Proc Nutr Soc 60, 515-525.

42. Lawrence CE (2003) Is there a common mechanism of gastrointestinal nematode expulsion? Parasite Immunol $\mathbf{2 5}$, $271-281$.

43. Patel N, Kreider T, Urban JF, et al. (2009) Characterisation of effector mechanisms at the host:parasite interface during the immune response to tissue-dwelling intestinal nematode parasites. Int J Parasitol 39, 13-21.

44. Bequette BJ, Metcalf JA, Wray-Cahen D, et al. (1996) Leucine and protein metabolism in the lactating dairy cow mammary gland: responses to supplemental dietary crude protein intake. J Dairy Res 63, 209-222.

45. DeSantiago S, Torres N, Suryawan A, et al. (1998) Regulation of branched-chain amino acid metabolism in the lactating rat. J Nutr 128, 1165-1171.

46. Li P, Knabe DA, Kim SW, et al. (2009) Lactating porcine mammary tissue catabolizes branched-chain amino acids for glutamine and aspartate synthesis. $J$ Nutr 139, 1502-1509.

47. Davis TA, Fiorotto ML \& Reeds PJ (1993) Amino acid compositions of body and milk protein change during the suckling period in rats. J Nutr 123, 947-956.

48. López N, Sánchez J, Picó C, et al. (2010) Dietary L-leucine supplementation of lactating rats results in a tendency to increase lean/fat ratio associated to lower orexigenic neuropeptide expression in hypothalamus. Peptides $\mathbf{3 1}$, 1361-1367.

49. Ban H, Shigemitsu K, Yamatsuji T, et al. (2004) Arginine and leucine regulate p70 S6 kinase and 4E-BP1 in intestinal epithelial cells. Int J Mol Med 13, 537-543.

50. Naomoto Y, Yamatsuji T, Shigemitsu K, et al. (2005) Rational role of amino acids in intestinal epithelial cells. Int J Mol Med 16, 201-204.

51. Maruyema GM \& Phillips PH (1948) Reproduction and lactation studies with rats fed natural and purified rations. $J$ Nutr 36, 613-623.

52. LeClerc J, Chanussot B, Miller ML, et al. (1989) Effects of protein level, methionine supplementation and carbohydrate type of the diet on liver lipid and plasma free threonine contents in the lactating rat. Reprod Nutr Dev 29, 269-276.

53. Astrup A \& Tremblay A (2009) Energy metabolism. In Introduction to Human Nutrition, 2nd ed., pp. 31-48 [MJ Gibney, SA Lanham-New, A Cassidy and HH Vorster, editors]. Oxford: Wiley-Blackwell. 